\title{
CONVENTIONAL WISDOM: Putting National Party Convention RATINGS IN CONTEXT
}

\section{Jill A. Edy and Miglena Daradanova}

This paper places broadcast major party convention ratings in the broader context of the changing media environment from 1976 until 2008 in order to explore the decline in audience for the convention. Broadcast convention ratings are contrasted with convention ratings for cable news networks, ratings for broadcast entertainment programming, and ratings for "event" programming. Relative to audiences for other kinds of programming, convention audiences remain large, suggesting that profitmaking criteria may have distorted representations of the convention audience and views of whether airing the convention remains worthwhile.

Over 80 percent of households watched the conventions in 1952 and $1960 \ldots$... During the last two conventions, ratings fell to below 33 percent. The ratings reflect declining involvement in traditional politics. ${ }^{1}$

Oh, come on. At neither convention is any news to be found. The primaries were effectively over several months ago. The public has tuned out the election campaign for a long time now....Ratings for convention coverage are abysmal. Yet Shales thinks the networks should cover them in the name of good citizenship? ${ }^{2}$

It has become one of the rituals of presidential election years to lament the declining television audience for the major party conventions. Scholars like Thomas Patterson have documented year-on-year declines in convention ratings and linked them to declining participation and rising cynicism among citizens, asking what this means for the future of mass democracy. ${ }^{3}$ Journalists, looking at conventions in much the same way, complain that conventions are little more than four-night political infomercials, devoid of news content and therefore boring to audiences and reporters alike. ${ }^{4}$ Some have suggested that they are no longer worth airing. In contrast, some scholars have argued for the importance of political conventions as a unique opportunity for nomi-

Jill $A$. Edy is an associate professor and Miglena Daradanowa is a doctoral student in the Department of Communication at the University of Oklahoma.

JEMC Quarterly Vol. 86, No. 3 Autumn 2009 499-512 C2009 AEJMC 
nees to present themselves to a large audience. ${ }^{5}$ Despite the debate over these important issues, no published scholarship in media and politics or mass political behavior has examined declining convention ratings in any detail.

The conventional wisdom that attributes declining convention viewership to declining participation, rising cynicism, or boring conventions looks sound enough at first glance. Yet the explanations seem reductionist when reconsidered in light of the dramatic changes in the American media system since the mid-1970s. Even as the modern primary system was emerging and voter turnout declining, cable television technology and programming were growing exponentially. In 1985, not quite $43 \%$ of American households received on average about nineteen channels with cable. In 2004, $68 \%$ of households received on average 100 channels, a figure that does not take into account direct broadcast satellite. In this environment of expanded consumer choice, virtually no television programming draws an audience as large as those of the three-network era.

This paper places convention ratings in the broader context of the changing media environment from 1976 until 2008 in order to present a more nuanced view of the decline in audience for the convention. Broadcast convention ratings are considered in the context of convention ratings for cable news networks, ratings for broadcast entertainment programming, and ratings for "event" programming. These data do not allow a test of alternative explanations for audience decline, but they do offer some important correctives to the assumptions made by journalists and scholars about the convention audience. They show that, relative to audiences for other kinds of television programming, convention audiences remain quite large and suggest that profit-making criteria may have distorted representations of the convention audience and thus democratic discourse about whether the convention is "worth" airing.

Conventional Wisdom
Many people ascribe the emergence of modern political conventions to the Democrats' experience in Chicago in 1968. Torn apart over civil rights and the Vietnam War, the party's convention disintegrated into violence in full view of a live television audience. In the aftermath, the modern primary system was created, and control of a party's image before the cameras became increasingly important. Both changes contributed to charges that modern conventions are "boring."

Certainly, the audience for the national party nominating conventions has declined in size over the last thirty years. ${ }^{7}$ Equally certainly, academic research has revealed signs of political disaffection such as decreasing public trust in government ${ }^{8}$ and declines in civic participation ${ }^{9}$ during the same time period. Academic scholarship also supports the argument that conventions are no longer newsworthy. The modern primary system determines the nominee long before the convention is held, and the campaign season itself is interminably long which, according to Patterson, both bores and disillusions voters. ${ }^{10}$ Because the nominees are long-since designated and the content of floor speeches is carefully controlled by 
party managers, this situation may be one of the few where reporters publicly agree with critical scholars ${ }^{11}$ that their news is being managed by political elites. Because conventions are so carefully managed, some reporters argue there is little chance that news will be made there (although it might reasonably be pointed out that many other "news events" share this quality, notably the State of the Union address). ${ }^{12}$ Thus, according to these reporters, the convention has little appeal to news audiences. ${ }^{13}$ Timmerman and Weier combine these arguments about cynicism and newsworthiness, arguing that cynical media coverage of conventions drives some potential viewers away. ${ }^{14}$

Although the evidence is circumstantial, these explanations for why convention audiences have substantially declined over the last three decades certainly look plausible. Yet they fail to consider the dramatically changed media environment. There are at least two reasons to question the conventional wisdom about convention audiences. In 1999, Baum and Kernell's study of the impact of cable television on audiences for the State of the Union address found that the decline in audience size was better explained by the growth of cable than by the growth in public cynicism and distrust. Prior recently described the impact of expanding media choices on the political knowledge and behavior of citizens both individually and collectively, noting that newer media technologies allow the disinterested to ignore political information much more efficiently than they once could. Historian Kenneth Cmiel made the same sort of argument with regard to the famous Lincoln and Douglas debates of 1858. In that era, politics served as a form of entertainment for a public with relatively few entertainment options. Patterson, too, noted the growing competition for citizens' time and attention..$^{15}$ It therefore seems plausible that convention audiences, like television audiences more generally, spread themselves thinner in the modern, multichannel universe than they did in the three-network universe of the 1970s. This raises two questions:

RQ1: What proportion of the television audience watches the national conventions on cable?

RQ2: How does the decline in audience size for broadcast convention coverage compare to the declines for broadcast entertainment programming?

A second reason to question the conventional wisdom is that most journalists and academics describe the size of the audience relative to previous convention audiences. Even though modern audiences for all types of programming are substantially smaller than they were in the broadcast era, reporters and scholars tend not to consider the size of the audience in absolute terms. Nor do they consider how the size of the convention audience compares to the audience for other types of programming, particularly event programming such as major sporting events. ${ }^{16}$ Moreover, some make the mistake of considering the audience 
size for individual networks rather than the audience size for the event itself. ${ }^{17}$ The convention is a single event covered by more than one media organization. Dividing the audience by network is meaningful mainly in terms of the distribution of advertising revenue, a consideration important to network executives but not to those who consider the democratic functions of political conventions. This raises a second set of questions:

RQ3: How big is the convention audience relative to "event" programming such as the summer Olympics?

RQ4: How does convention coverage fare in competition with broadcast entertainment programming that airs opposite it?

The results shed light on the continuing relevance of modern political conventions and help to answer the question of whether the conventions are "worth" airing.

\section{Methods}

The analysis begins with 1976 for two reasons. The delegate selection system was substantially changed between 1968 and 1972, and the 1972 conventions may have attracted unusual interest as the first to use the new system. Thus, the modern, "boring" convention seems more likely to have made its appearance in 1976. Second, cable television was not a factor in 1976, so this date offers a ratings benchmark prior to the creation of the first cable news network, CNN, in 1980. Convention ratings were tracked through 2008.

Convention ratings are contextualized using three other types of data. First, when they became available, cable news channel ratings were included. Second, ratings for the week of regular television preceding the first convention were considered. Selecting a comparable week of "regular" television is difficult because the size of the television audience varies seasonally. Although now more aggressively programmed than in previous eras, summer is traditionally a low-rated period compared to other time periods, supposedly because good weather and family vacations take people away from their television sets. ${ }^{18}$ Thus, comparing the convention ratings to annual averages would be inappropriate. However, one might argue that comparing convention coverage to an average week of summer re-runs or inexpensive reality programming is also unfair since convention coverage is not really everyday network fare. It might be better classed as "event television."

To see how the convention fared against "event" programming, the study compares the size of the convention audience to that of the opening night of the summer Olympic Games. The summer Olympics are held in the same years as the conventions and typically near the same dates. Networks pay exorbitant fees for the rights to broadcast the Games, suggesting that they expect to draw large audiences to cover the costs of their investment. ${ }^{19}$ Given that commentators have typically emphasized the low ratings for convention coverage and some have suggested that airing 
the conventions is no longer worthwhile, ${ }^{20}$ it would be surprising to find that the average size of the convention audience was competitive with the Olympic audience for any night of the Games. The opening night of the Games was selected for two reasons. First, it is the only night of the Games for which consistent data are available across the entire time frame of the study. Second, ratings on competition nights are affected by the schedule of competition, whether American athletes are competitive for medals in the scheduled events, and the even more mercurial factor of athletic personalities, making the selection of an "average" competition day an untenable approach. The opening ceremonies usually receive high ratings but not higher than certain competition days. Because the 2008 Democratic convention was held the week after the Beijing Olympic Games ended, it is possible to see, for this year at least, how the opening ceremonies compare to the second week of competition. ${ }^{2 t}$

Findings are expressed in Nielsen rating points. These are the only reliable audience measures to cover the entire time frame, and because a Nielsen rating point represents audience size as a proportion of total television households, ${ }^{22}$ expressing measures in rating points controls for the growing number of television households over the years. Nielsen's measurement system underwent changes in 1987, when the "people meter" came into use. Prior to that time, Nielsen's set-top boxes measured whether the set was turned on and, if so, what channel it was tuned to. After 1987, people meters recorded who was in the room with the set when it was on, in addition to what channel the set was tuned to. ${ }^{23}$ In 1988, some journalists claimed that the people meter devices resulted in lower-than-usual ratings for the summer Olympics. ${ }^{24}$ Thus, the following analysis of trends in viewership considers pre-1988 and post-1988 trends separately as well as overall trends. When comparing coverage at a specific point in time, the assumption is that the people meters affected audiences for different types of programming in the same kind of way. In other words, if the people meter reduced the audience estimate for the 1988 Olympics, it probably reduced the estimate for the 1988 conventions as well.

Ratings data for the political conventions were collected from Variety. From 1988 on, Variety has published tables of primetime ratings for the three major networks. ${ }^{25}$ Prior to that, ratings information was collected from articles on ratings published in Variety. In cases where more than one report was available, the ratings were compared and, if dissimilar, the report that explicitly mentioned "Nielsen ratings" was preferred. The average ratings for the four days of broadcast convention coverage were calculated by first averaging the ratings of each network and then adding the ratings for each network to produce an overall broadcast rating. This method of calculation helped to contend with the fact that in recent years, networks have often carried different amounts of convention coverage.

There are no reports of cable ratings in 1980 when CNN started its operations because the new medium's audience was too small to be picked up by existing measurements. ${ }^{26}$ Cable ratings data from 1984 on 
were collected from Nexis sources, news agency reports (particularly the Associated Press), and hard copies of the industry publication Broadcasting (later Broadcasting and Cable). Once again, in cases where multiple, conflicting reports existed, those that specifically mentioned "Nielsen ratings" were preferred. The cable ratings reported between 1984 and 1996 are CNN ratings, while the ratings reported for the conventions from 2000 on include CNN, MSNBC, and Fox News. Just as Nielsen's broadcast rating points represent a proportion of all television households, Nielsen's cable ratings represent a proportion of all basic cable subscribers, which is always smaller than the total television home universe. Therefore, to make the ratings comparable, cable ratings were converted to represent a percentage of the total number of TV households in the United States. The number of television and basic cable households in the United States throughout the years was obtained from the Web site of the National Cable and Television Association. ${ }^{27}$

Ratings for primetime broadcast programming the week before the non-incumbent convention (the first convention to be held each election year) were collected from the tabular data provided in Variety since 1988. In earlier years, data could not be compiled because crucial information was often inconsistent or missing. In order to compare primetime audiences in a "regular" week to those of a convention week, the average primetime rating for each network (provided in Variety's tables) was summed to get the overall broadcast rating for the night. Then, average overall ratings for Monday through Thursday nights, the same nights the convention would be covered the following week, were computed.

Ratings data on the Olympics were collected from news agencies (e.g., UPI and AP) and national newspapers (New York Times and Washington Post). Ratings data for the 1980 Moscow Olympics are unavailable due to the U.S. boycott; consistent coverage of the Games was not offered on American television. ${ }^{28}$

Figure 1 shows the decline in audience others have observed. Between 1976 and 1988, the major broadcast network (ABC, NBC, CBS) audience for the convention declined by $28 \%$. Between 1988 and 2000, the decline was even more steep, $41 \%$. It is also easy to see why, from a broadcast network perspective, the economic performance of the conventions is dismal. Assuming that the audience was evenly split among the three networks, an average night of coverage of the 2000 conventions earned a 4.0 rating. In comparison, a night of Will $\mathcal{E}$ Grace reruns from the week before earned ratings that ranged from 5.1 to 8.2 .

However, the purpose of this paper is to provide some perspective on the declining size of convention audiences, and Figure 1 begins this process by offering two comparison points alongside the broadcast audience for major network coverage. First, it answers RQ1, showing how the rise of cable news networks has affected the overall audience for political conventions. The evidence shows that at least some of the decline in broadcast audiences for the conventions is made up for by the growing audience for cable convention coverage. According to the figure, in 1984 


\section{FIGURE 1}

Comparison Ratings for Broadcast Convention Coverage, Combined Cable and Broadcast Convention Coverage, and Regular Broadcast Prime-time Programming

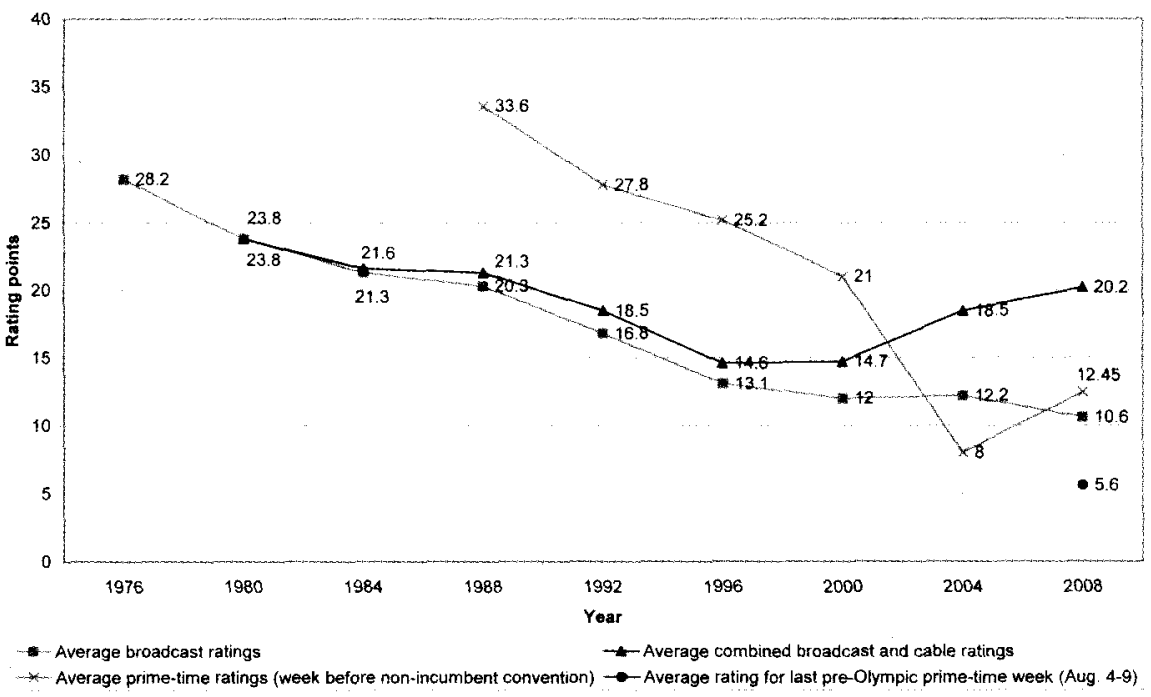

CNN accounted for barely $1 \%$ of the total audience for the convention (.3 of a ratings point). By $1988, \mathrm{CNN}$ viewers were nearly $5 \%$ of the total audience (1 ratings point). By 2008, nearly half of the convention audience was watching on cable, and during the first two days of the Republican convention, the cable audience was bigger than the broadcast audience. ${ }^{29}$

Including the cable audience changes the interpretation of the data considerably. Were one simply looking at the broadcast audience, one would conclude that the 2008 conventions had the smallest audience the conventions had ever drawn. One might be quite concerned about this given that this was an open election to replace a highly unpopular president during the worst economic downturn since the Great Depression. However, when the cable audience is figured in, the conventions had their largest audience in twenty years. With cable viewership figured in, the decline in audience between 1988 and 2000 is $31 \%$, not $41 \%$. Even more striking, the drop in broadcast audience over the entire time frame is more than $62 \%$, but when cable is included, the decline is only $28 \%$. Including the cable ratings along with the broadcast ratings for convention coverage suggests that the ratings have more than stabilized-they are actually rising.

The rest of the information included in Figure 1 addresses RQ2. The growth in cable television access and programming has siphoned audiences away from the traditional broadcast networks. ${ }^{30}$ While networks still typically outdraw cable channels, the size of their audience in absolute terms has declined substantially. The essential mechanics of 
the decline are simple enough: with more programming choices available, each program draws a smaller audience. In 1976, there was almost nothing to watch on television during convention weeks except the convention. By 2008, there were dozens of choices. Moreover, even as cable television has expanded its reach and its program offerings, other technologies such as VCRs, DVD players, video game systems, and the Internet have come to compete with broadcast television for audiences' leisure time.

The data presented in Figure 1 provide perspective on just how steep the decline in convention audiences has been relative to the overall decline in broadcast television viewership. One can see that the conventions do not draw as well as entertainment programming on network television until 2004. Ratings data from the week before the first convention show that the average primetime rating for broadcast summer entertainment programming is between six and twelve points higher than the average broadcast convention rating between 1988 and 2000 . One might therefore expect that as entertainment programming choices expanded with the growth of cable, convention ratings would be especially hard hit. However, the figure paints a more complex picture. Between 1988 and 1996, the figure supports the conventional wisdom. The summer broadcast ratings for the week before the first convention fell only $15 \%$ (from 33.6 to 25.2), while the ratings for the conventions fell by twice that much, more than $31 \%$ (from 21.3 to 14.6). Between 1996 and 2000, however, network ratings dropped $23 \%$ (25.2 to 21 ) while convention ratings fell by only $8 \%$ (14.6 to 14.5 ). In 2004 , the average size of the convention audience on broadcast television was actually larger than the average broadcast entertainment programming audience for the previous week. In 2008, the high ratings for the second week of the Olympic Games meant that the average broadcast primetime audience size for the week before the first convention was slightly larger than the average broadcast audience size for the conventions themselves. However, the last week of "regular" summer programming before the Games began drew a broadcast audience barely half as big as the conventions would draw three weeks later. In other words, at the moment that broadcast network ratings went into free fall, the decline in convention audience became more gradual. Cable trends present an even brighter picture, for they suggest that the low point in viewership occurred in 1996 and that since then the audience has stabilized and may have even grown if recent numbers are not purely a product of current events.

RQ3 asks how the size of the audience for the national party conventions compares with the size of the audience for other events. Figure 2 compares average convention week ratings (for cable and broadcast combined) with the ratings for the opening night of the summer Olympics.

The evidence shows that the conventions have often been competitive with the Olympic opening night in audience drawing power. In 1976, the conventions had a larger average audience size than the opening night of the Montreal Games. The 1984 convention audience was only marginally smaller than the audience for the opening night of the 


\section{FIGURE 2}

Overall Convention Coverage Ratings v. Olympic Opening Ceremony Ratings

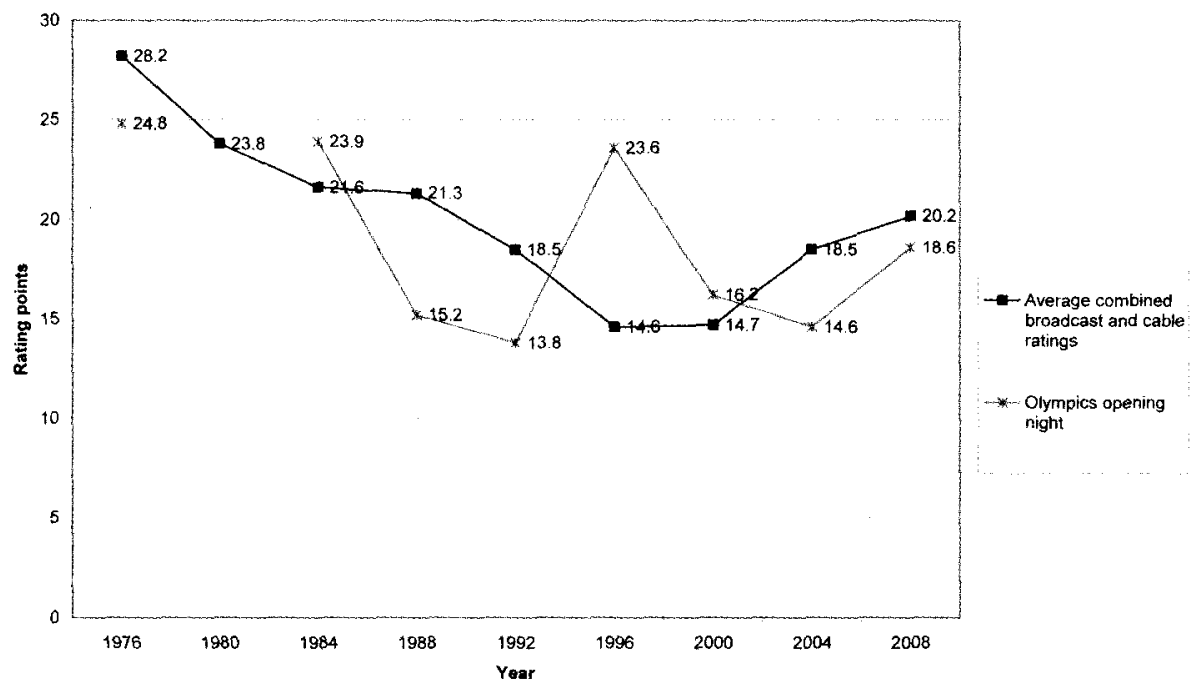

Los Angeles Games (21.6 v. 23.9). The conventions outdrew the Seoul (1988) and Barcelona (1992) Olympics' opening nights. In 1996, the opening of the Atlanta Olympics significantly outdrew the conventions, but in 2000, the audience for the opening ceremonies of the Sydney Olympics was again only marginally bigger than the convention audience (16.2 v. 14.7). Although the ratings for the Beijing opening ceremonies were the highest ever for a non-U.S. opening ceremony, ${ }^{31}$ the average convention audience was actually bigger. In general, only opening ceremonies for Olympic Games held in the United States outdraw the conventions, the Sydney Games being the lone exception.

By this point, it is perhaps unsurprising that the conventions can do quite well against standard network fare as well when the overall audience is considered rather than the viewership of a single network (RQ4). Consider how the two lowest-rated conventions, 1996 and 2000 , stack up against entertainment programming from the previous week. In 1996, the overall convention ratings of 14.6 trounced pre-season Monday Night Football. The Dallas-Kansas City game before the Republican convention earned an 8.8 rating, and the Minnesota-Miami game before the Democratic convention earned a 9.6. In 2000, the average broadcast only convention rating (12) was beaten by only two programs from the previous week. Who Wants to Be a Millionaire, which aired twice that preceding week, earned ratings of 13.85 and 14.8, and Survizor earned a 15.95. No other program aired by the networks broke the 10 point mark. When the cable ratings are figured in (14.7), only the audience for Survivor is clearly bigger than the convention's.

Comparing the convention head-to-head with other broadcast programming is difficult because networks typically make very similar 
decisions about how much and what aspects of the conventions to cover. Thus, even today it is often the case that during certain hours, there is nothing on broadcast television except the convention. The 2000 conventions, however, were counterprogrammed to some extent and so offer some insight into RQ4. Competing head-to-head against entertainment programming on broadcast television, the convention did poorly when carried by a single network (broadcast average ratings of $4.0 \mathrm{v}$. an average of 5.3 for each network entertainment program aired opposite it). Carried on two networks, it became competitive with entertainment programming (broadcast average ratings of $8.2 \mathrm{v}$. an average of 5.1 for the opposing network entertainment program). Here, the 2000 conventions might be seen as outperforming the 1992 conventions, the last ones before them that were aggressively counterprogrammed. In 2000, when a convention was aired on two networks, its broadcast rating beat every entertainment program aired opposite it, but in 1992, it only won three of seven matchups even when carried on two networks. Carried on all three networks, the 2000 conventions' ratings resemble those for highly rated network programming and event programming (broadcast average rating of 12.1). Nevertheless, convention coverage lost a substantial portion of its "lead in audience." Typically, half or more of viewers changed the channel when the convention came on, although whether some of them defected to another form of convention coverage is unknown.

\section{Discussion}

In this study, we have attempted to offer a perspective on declining convention ratings that accounts for important changes in the television environment that have occurred over the last three decades. Although the total size of the convention audience has declined by about $28 \%$ over the last thirty years, many of the losses in the broadcast audience for the conventions have been offset by citizens watching the more extended coverage offered on the cable news channels. The decline in convention audience may continue as a generation of older, more engaged citizens gives way to a younger, less involved public, ${ }^{32}$ but over the last eight years, the convention audience has stabilized and even grown slightly. Meanwhile, the audience size for network entertainment programming in the week prior to the conventions has continued to plummet.

One might also consider Internet convention coverage, which is unaccounted for here. In 2000, Patterson found that very few citizens watched Internet coverage. ${ }^{33}$ However, Internet access has not yet reached the levels of cable penetration, and the broadband access needed for convenient video viewing is still in an early stage of growth. Diffusion of innovation curves ${ }^{34}$ would suggest that early audiences for Internet convention coverage would be small and very motivated and that rapid growth in the audience, were it to occur, would follow an early period of modest expansion.

When one considers not rate of decline but the absolute size of the convention audience, one finds that it is quite comparable to another, similarly scheduled type of "event programming," the opening ceremonies of the summer Olympics. Unless the Olympics are held in the United States, 
the convention typically draws audiences bigger than those for the ceremonial opening night. One might argue that the Olympics, carried on only one channel, face more competition than the conventions, but it is also likely that the Olympics are better promoted than the conventions. Because exclusive broadcast rights to the Olympics are purchased at substantial cost, it is reasonable to expect the Games to be highly and positively promoted. In contrast, because the conventions are a news event covered by all news outlets, the profits from airing it (or promoting it), cannot be retained by a single network, giving networks low incentive to promote it. Indeed, some prominent journalists have denigrated the conventions. In 1996, $A B C^{\prime}$ s Ted Koppel walked out of the Republican convention, saying there was no news there ${ }^{35}$ In 2004, the anchors of both NBC and CBS news decried the conventions as "prepackaged" and "infomercials." 36

When convention coverage is treated as just another primetime program, it fares quite badly in the ratings, which is unsurprising. It is not itself regularly scheduled network programming to which viewers tune in every week, nor is it likely to be as heavily promoted as network special programming. Indeed, while some of the decline in convention ratings may be a result of audiences being able to tune out political information more efficiently than in the broadcast era, ${ }^{37}$ some may be because the convention is harder to find than it used to be. Not only are there many more channels to surf, but, according to Patterson, network convention coverage declined from twenty-five hours in 1976 to twelve hours in 1984 to five hours in $2000 .^{38}$ Networks may have seen this as cherry-picking the most exciting moments of the convention in order to boost ratings, and for those who make one or both conventions "appointment television," the reduced coverage will not matter much. However, a channel surfer today may have lower odds of running across convention coverage and tuning it in than surfers of yesteryear, and Patterson found that about half the convention audience in 2000 was inadvertent. Audiences may find the event easier to stumble across when it is covered in more places; moreover, they may perceive it as more important and thus worthy of attention when it receives coverage on multiple networks. When the convention is treated as a news event, that is, an event worthy of coverage by all three networks, its audience size begins to resemble that of other event programming and highly rated network programming.

Most of the ways that scholars, journalists, and perhaps network executives have looked at convention audiences have raised alarms about audience decline. Year-after-year declines in ratings and ratings for individual networks give substantial cause for concern. However, virtually no programming today generates audiences as large as those of the three-network era. When considered in light of the changing media environment, the conventions continue to generate audiences that are about as large as those of highly popular entertainment programs and at least one major sporting event. Unfortunately, convention coverage is less profitable to networks than other forms of programming because no single network can lay sole claim to the revenues generated by large 
convention audiences. Thus, debates over whether the conventions are worth airing may be subtly invaded by economic concerns which seem inappropriate when considering the role of the conventions in the democratic process. Any single network program that earned the ratings the convention does would not be in danger of cancellation. More coverage on more networks makes the convention easier to find in a noisy media universe and indicates to citizens that the convention is an important event.

NOTES

1. Kevin Galvin, "Conventions Still Relevant in Info Age: American Politics of Our Time Played out on Partisan Stages," Seattle Times, July 30 , 2000, sec. A, p. 1.

2. Douglas B. O'Morain, "What if No One Watched?" Washington Post, August 5, 2000, sec. A, p. 17.

3. Thomas E. Patterson, Out of Order (New York: Knopf, 1992); Thomas E. Patterson, "Lessons from the Last Convention," http:/ / www. vanishingvoter.org/VV2000/Papers/convention_lessons.pdf (accessed December 6, 2004); Thomas E. Patterson, The Vanishing Voter: Public Involvement in an Age of Uncertainty (New York: Knopf, 2002).

4. See for example, Ed Bark, "Networks Put New Spin on Ratings," Dallas Morning News, August 3, 2000, sect. Overnight, p. 43A.; Bill Carter, "Faced with Poor Ratings, Networks Soul Search," New York Times, September 3, 2004, sec. A, p. 19; O' Morain, "What if."

5. Karen Lane DeRosa and Dianne G. Bystrom, "The Voice of and for Women in the 1996 Presidential Campaign: Style and Substance of Convention Speeches," in The Electronic Election: Perspectives on 1996 Campaign Communication, ed. Lynda Lee Kaid and Dianne Bystrom (Mahwah, NJ: Lawrence Erlbaum Associates, 1999), 97-112; E. D. Dover, Missed Opportunity: Gore, Incumbency, and Television in Election 2000 (Westport, CT: Praeger, 2002); E. D. Dover, The Presidential Election of 1996: Clinton's Incumbency and Television (Westport, CT: Praeger, 1998).

6. Jill A. Edy, Troubled Pasts: News and the Collective Memory of Social Unrest (Philadelphia, Temple University Press, 2006); Patterson, Out of Order.

7. Patterson, Out of Order; Patterson, Vanishing Voter.

8. See, for example, Joseph N. Cappella and Kathleen Hall Jamieson, Spiral of Cynicism: The Press and the Public Good (New York: Oxford University Press, 1997).

9. See, for example, Robert D. Putnam, Bowling Alone: The Collapse and Revival of American Community (New York: Simon and Schuster, 2000); Patterson, Vanishing Voter.

10. Patterson, Out of Order.

11. See, for example, W. Lance Bennett, News: The Politics of Illusion (White Plains, NY: Longman, 1983).

12. For a more general discussion of the planned quality of most news coverage, see Edward J. Epstein, News from Nowhere: Television and the 
News (New York: Random House, 1973); Gaye Tuchman, Making News: A Study in the Social Construction of Reality (New York: Free Press, 1978).

13. See, for example, James Bennet, "The Republicans: The Broadcasts: 'Nightline' Pulls the Plug on Convention Coverage," New York Times, August 15, 1996, sec. A, p. 19; O'Morain, "What if."

14. David M. Timmerman and Gary M. Weier, "The 1996 Presidential Nominating Conventions: Good Television and Shallow Identification," in The 1996 Presidential Campaign: A Communication Perspective, ed. Robert E. Denton (Westport, CT: Praeger, 1998), 77-100.

15. Matthew A. Baum and Samuel Kernell, "Has Cable Television Ended the Golden Age of Presidential Television?" American Political Science Review 93 (May, 1999): 99-114; Markus Prior, Post Broadcast Democracy: How Media Choice Increases Inequality in Political Involvement and Polarizes Elections (New York: Cambridge University Press, 2007); Kenneth Cmiel, Democratic Eloquence: The Fight over Popular Speech in Nineteenth Century America (New York: W. Morrow, 1990); Patterson, Vanishing Voter.

16. See, for example, Galvin, "Conventions Still Relevant"; Patterson, Vanishing Voter.

17. See, for example, Bark, "Networks Put."

18. The Fourth of July ratings week is typically the lowest rated of the year; see Rick Kissell, "TV Takes Lumps on 4th," Daily Variety, July 11, 2007, p. 6. See also William S. Rubens, "A Guide to TV Ratings," Journal of Advertising Research 18 (February, 1978): 11-19; Gary Levin, "Don't Sweat Summer TV Ratings: Audiences Are Up," USA Today, July 31, 2008, sec. D, p. 1.

19. NBC paid nearly $\$ 900$ million to broadcast the Beijing Games; see Allison Romano, "Olympic Proportions: NBC's Plans for a Beijing Bonanza," Broadcasting and Cable, August 2, 2008, http://www.broad castingandcable.com/article/CA6583895.html?q=Broadband +video (accessed August 13, 2008).

20. See, for example, Galvin, "Conventions Still Relevant"; Patterson, Vanishing Voter; O'Morain, "What if"; Carter, "Faced with."

21. Because the Games aired the week before the first convention, we offer two comparison points of "regular" television for 2008. Continuing the trend line for the week before the first convention, we include the second week of Olympic competition, which aired immediately before the Democrats' convention. We also include a data point for the last week of "regular" television to air before the Olympic Games began, which was the week of August 4-9.

22. "Ratings 101, About Nielsen Media Research," Nielsen Media Research Web site, http://www.nielsenmedia.com/index.html (accessed December 6, 2004).

23. "Cap/ABC Ending Service; Nielsen Dropping Diaries in September for People Meters," Communications Daily, January 12, 1987, p. 3.

24. Kathryn Baker, "Olympics Start Disappointing for NBC," The Associated Press, September 21, 1988, Lexis-Nexis Academic Universe (accessed February 4, 2005). 
25. In 2008, the relevant tables were missing from Variety for the convention weeks. Ratings data were retrieved December 15, 2008, from http://tvbythenumbers.com/, which provided Nielsen ratings data for the broadcast networks for the Democratic convention. Cable ratings and broadcast ratings for the Republican convention were calculated based on audience numbers reported by http://www.allthingscnn.com/ 2008/09/ratings-2008-democratic-national.html (for the Democrats, retrieved May 27, 2009) and http://www.huffingtonpost.com/ 2008/09/06/fox-news-sweeps-the-repub_n_124533.html (for the Republicans, retrieved May 27, 2009).

26. Morrie Gelman, "Measuring the Cable TV Audience," Variety, August 20, 1980, p. 54.

27. National Cable and Telecommunications Association (NCTA), Industry Statistics, Television and Cable Households (n.d.), http:/ / www. ncta.com/industry_overview/indStats.cfm?statID=1 (accessed December 6,2004$)$.

28. "A Big Yawn in America," US News \& World Report, August 4, 1980, 21.

29. http: / / www.huffingtonpost.com/2008/09/06/fox-news-sweepsthe-repub_n_124533.html. Note that the Republican convention was held Tuesday through Thursday in 2008. The Monday night opening was cancelled due to Hurricane Gustav.

30. James G. Webster and Patricia F. Phalen, The Mass Audience: Rediscovering the Dominant Model (Mahwah, NJ: Lawrence Erlbaum, 1997).

31. "Record Ratings for NBC's Olympic Opening Ceremony," http: / / www.thrfeed.com/2008/08/ceremony-rating.html (accessed January 8,2009 ).

32. See Patterson, "Lessons from."

33. Patterson, Vanishing Voter.

34. Shearon A. Lowery and Melvin L. DeFleur, Milestones in Mass Communication Research: Media Effects (White Plains, NY: Longman, 1995).

35. Bennet, "The Republicans."

36. Carter, "Faced with."

37. Prior, Post-Broadcast Democracy.

38. Patterson, Vanishing Voter. 